\title{
Arginase as a Potential Target in the Treatment of Alzheimer's Disease
}

\author{
Baruh Polis, Abraham 0. Samson \\ The Azrieli Faculty of Medicine, Bar-Ilan University, Safed, Israel \\ Email: baruhpolis@gmail.com
}

How to cite this paper: Polis, B. and Samson, A.O. (2018) Arginase as a Potential Target in the Treatment of Alzheimer's Disease. Advances in Alzheimer's Disease, 7, 119-140.

https://doi.org/10.4236/aad.2018.74009

Received: September 28, 2018

Accepted: November 19, 2018

Published: November 22, 2018

Copyright (c) 2018 by authors and Scientific Research Publishing Inc. This work is licensed under the Creative Commons Attribution International License (CC BY 4.0).

http://creativecommons.org/licenses/by/4.0/

(c) (i) Open Access

\begin{abstract}
Alzheimer's disease (AD) is a slowly progressive, neurodegenerative disorder with an insidious onset that is characterized by severe decline in memory, thinking and reasoning skills. Advanced age is a prominent risk factor for $\mathrm{AD}$ and other metabolic diseases, such as type II diabetes and atherosclerosis. Their causal mechanisms are multifaceted and not fully understood. The precise pathophysiology of $\mathrm{AD}$ remains a mystery despite decades of intensive investigation. Thus far, there is no truly successful AD therapy. Arginase is the central enzyme of the urea cycle. Recent studies have identified arginase function in the brain and associated this enzyme with the development of neurodegenerative diseases. Upregulation of arginase has been shown to contribute to endothelial dysfunction, ischemia-reperfusion, atherosclerosis, diabetes, and neurodegeneration. Other state-of-the-art discoveries of the precise molecular machinery of neurodegeneration have provided new directions for the rational development of innovative therapeutic strategies in the treatment of common neurodegenerative diseases. In this context, the regulation of arginase activity appears to be a universal approach in interfering with the pathogenesis of $\mathrm{AD}$ and providing relief for it and other metabolic disorders. Therefore, the enzyme represents a novel therapeutic target. Arginase inhibition has been shown to reverse amyloid-driven neuronal dysfunction and microgliosis and prevent the development of other $\mathrm{AD}$ symptoms in rodent models of $\mathrm{AD}$. Consequently, the methodology represents a promising direction for clinical development.
\end{abstract}

\section{Keywords}

Alzheimer's Disease, L-Norvaline, L-Arginine, Arginase

\section{Introduction: Alzheimer's Disease as a Metabolic Disorder}

Alzheimer disease (AD) is the most common cause of dementia in the elderly 
[1]. Clinical and pathological studies point to the presence of a long-term preclinical stage of the disease, which starts prior to the onset of detectable cognitive deficiency. There is no complete scientific consensus regarding the etiology of AD. At present, a prevailing etiologic model of the disease is one that is referred to as the "amyloid hypothesis". According to this model, amyloid-beta (A $\beta$ ) deposition begins decades prior to the onset of clinical symptoms. This silent period of preclinical $\mathrm{AD}$ is followed by a buildup of hyperphosphorylated Tau protein and prominent neurodegeneration [2]. The amyloid cascade hypothesis is an influential model, regardless of several contradictions in it and the failure of countless clinical trials that are predicated upon its central doctrine. Nevertheless, during the last decade, numerous studies have been published that focus on the relationships between $\mathrm{AD}$ and metabolic disorders such as diabetes, obesity, and hypertension, etc.

Recent clinical and experimental data prove that neurodegenerative and metabolic diseases display coexisting metabolic dysfunctions [3]. The latest epidemiological studies indicate the comorbidity of $\mathrm{AD}$ and diabetes mellitus beyond any doubt [4]. Moreover, obesity and AD are likely to have similar causative mechanisms [5]. Likewise, there is epidemiologic and clinical-pathological evidence suggesting that atherosclerosis and AD share a common pathoetiology [6] [7].

Additionally, contemporary, cutting-edge laboratory methods provide convincing data pointing to substantial metabolic changes associated with $\mathrm{AD}$. Gas chromatography coupled with mass spectrometry of AD patients' serum revealed substantial metabolic differences between $\mathrm{AD}$ patients and healthy controls and elucidated some pathological mechanisms underlying the disease [8]. Significant changes in the levels of 23 metabolites have been detected. Metabolic pathway analysis has indicated the involvement of critical metabolic pathways, such as energy deficiencies, oxidative stress, and hyperammonemia. Consequently, nutritional behavior has been suggested as a triggering factor in the presymptomatic stages of $\mathrm{AD}[9]$.

An additional hypothesis emphasizing impairment of bioenergetic metabolism as a key contributing mechanism to the pathogenesis of $\mathrm{AD}$ has recently been proposed [10]. According to this hypothesis, AD is characterized by a combination of several interrelated pathological events that include bioenergetic, metabolic, neurovascular, and inflammatory processes. Other researchers point out that brain hypometabolism occurs decades before clinical manifestation, suggesting that metabolic dysfunction is an important contributing factor to $\mathrm{AD}$ [11]. Moreover, accumulating data indicate that mitochondrial dysfunction, which is an early marker of $\mathrm{AD}$, plays a role in neuronal dysfunction [12]. $\mathrm{Cy}$ tochrome $c$ oxidase activity was shown to be reduced in the brains of $\mathrm{AD}$ mice [13]. There is evidence that $\mathrm{A} \beta$-driven inhibition of the enzyme activity is a result of direct binding to one of its subunits [14]. The proposed model of interaction between $\mathrm{A} \beta$ and cytochrome $\mathrm{c}$ oxidase explicates the characteristic metabolic dysfunction detected in $\mathrm{AD}$ brains. 
Current therapeutic schemes address symptoms and focus on manipulating with cholinergic and glutamatergic neurotransmission. The U.S. Food and Drug Administration (FDA) has approved only two classes of medicines. Cholinesterase inhibitors belong to the first class, and the N-methyl-D-aspartate (NMDA) receptor antagonist memantine to the second (Table 1). All of them are palliative drugs that just ameliorate the cognitive decline but do not stop the development of the disease. Moreover, there are severe side effects associated with the drugs. Unfortunately, most of the clinical trials with beta-secretase 1 (BACE1) inhibitors have been terminated due to severe side effects. Moreover, monoclonal antibodies targeting $\mathrm{A} \beta$ have not demonstrated considerable efficacy [15]. State-of-the-art emerging strategies are focused on the preclinical stage, with the aims of reducing the rate of $\mathrm{A} \beta$ accumulation and neuroinflammation and normalizing the disordered neuronal metabolism (Table 1) [16].

Dozens of AD clinical trials are currently running in the U.S. Several of them test protocols that interfere with mitochondrial metabolism and energy balance, which is disordered in AD. Some utilize medicines (such as insulin) that are well known and widely used to treat other metabolic disorders. Others try to improve brain glucose metabolism by applying the hormone incretin [17]. These point to a trend toward the development of innovative drugs that are primarily capable of

Table 1. Current FDA-approved drugs and drugs in clinical trials (incomplete list) for the treatment of $\mathrm{AD}$.

\begin{tabular}{|c|c|c|}
\hline Current FDA-approved treatment for $\mathrm{AD}$ & & FDA approval (year) \\
\hline \multirow{2}{*}{ Acetylcholinesterase inhibitors } & Donepezil & 2006 \\
\hline & Rivastigmine & 2000 \\
\hline NMDA antagonists & Memantine & 2003 \\
\hline Novel medicines in clinical trials & & Status \\
\hline BACE1 inhibitors & E2609 & Phase III \\
\hline Inhibitors of APP production & Posiphen & Phase I \\
\hline Tau immunotherapy & ABBV-8E12 & Phase II \\
\hline $\mathrm{A} \beta$ immunotherapy & LY3002813 & Phase II \\
\hline $11 \beta$-HSD1 blocker & Xanamem & Phase II \\
\hline p38 MAPK Alpha Inhibitor & Neflamapimod & Phase I \\
\hline Butyrylcholinesterase inhibitors & Bisnorcymserine & Phase I \\
\hline Angiotensin-receptor blockers & Telmisartan & Phase I \\
\hline $\mathrm{A} \beta$ oligomer receptor antagonist & CT1812 & Phase I \\
\hline Mitochondrial activity and energy modulator & Oxaloacetate & Phase I \\
\hline Modulators of muscarinic receptors & VU319 & Phase I \\
\hline Nonsteroidal estrogen & S-equol & Phase I \\
\hline Nonsteroidal anti-inflammatory drugs & Salsalate & Phase I \\
\hline Bcr-Abl kinase inhibitor & Nilotinib & Phase I \\
\hline Modulators of protein kinase $\mathrm{C}$ & Bryostatin & Phase II \\
\hline Insulin administered as a nasal spray & Insulin & Phase II/III \\
\hline
\end{tabular}


interfering with the pathogenesis of $\mathrm{AD}$ and the associated disordered brain metabolism. Nevertheless, the lack of comprehensive analysis and specific methodology limit the development of effective AD therapy.

\section{L-Arginine Metabolism and Alzheimer's Disease}

L-arginine is a semi-essential, cationic amino acid that is heavily involved in vital physiological processes. Further to its principal role in protein biosynthesis, L-arginine is the final enzyme in the urea cycle, which converts toxic ammonia to urea for excretion (Figure 1), and it is a precursor of nitric oxide [18]. Moreover,

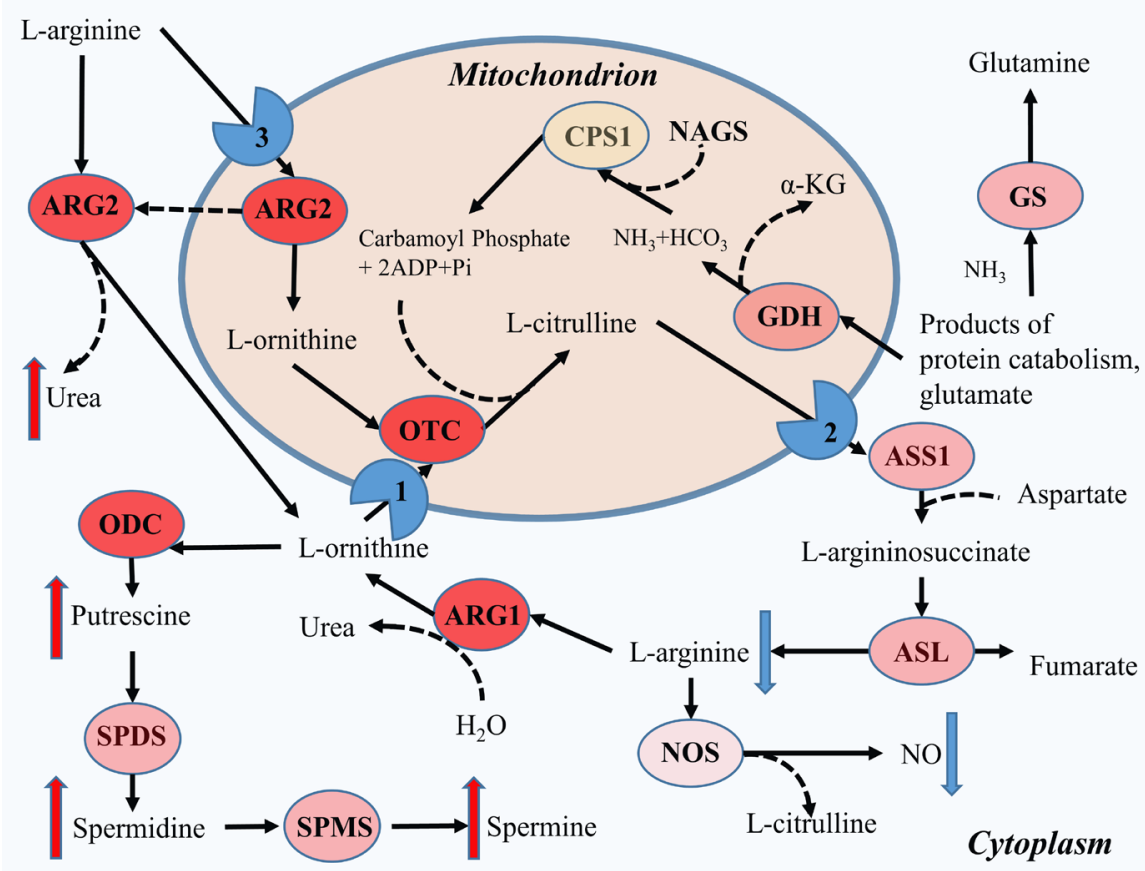

Figure 1. Metabolic fates of L-arginine in the $\mathrm{AD}$ brain. $\mathrm{L}$-arginine is cleaved by arginase to form urea and ornithine. Arginase is the final enzyme of the urea cycle. The primary function of the urea cycle is to produce urea from the nitrogenous waste products of protein metabolism. Two moles of ammonia are proceeded and one mole of urea is produced in one turn of the five-step cycle. The urea cycle comprises $\mathrm{N}$-acetylglutamate synthase (NAGS), which is an allosteric cofactor for the catalytic enzyme carbamoyl phosphate synthase (CPS1), and four other catalytic enzymes: ornithine transcarbamylase (OTC), argininosuccinate synthetase (ASS1), argininosuccinate lyase (ASL), and ARG1. NAGS, CPS1 and OTC are localized in the mitochondria, while ASS1, ASL, and ARG1 are in the cytosol. Two enzymes, OTC and CPS1, are present in very low concentrations in the mammal brain. Consequently, the brain lacks an effective urea cycle and the removal of ammonia relies upon glutamine synthesis by cytosolic glutamine synthetase (GS) [88]. Another mitochondrial enzyme, glutamate dehydrogenase (GDH), catalyzes the deamination of glutamate to $\alpha$-ketoglutarate $(\alpha-\mathrm{KG})$ and ammonia $\left(\mathrm{NH}_{3}\right)$. There are three transporters in the mitochondrial membrane that are critical for the correct functioning of the urea cycle: 1 ) the mitochondrial ornithine transporter (ORNT1); 2) the mitochondrial aspartate/glutamate carrier (Citrin); and the mitochondrial cationic amino acid transporter type 1 (CAT-1). Red arrows represent elevated levels of the substances; blue arrows designate reduced ones. The saturation of the circles' color reflects the level of activation (this is an arbitrary scale). 
it is an obligatory precursor for the synthesis of L-ornithine, L-proline, polyamines, creatine, etc. [19].

A new, unbiased approach focusing on lipidomics and metabolomics was applied to analyze the changes in postmortem brains in patients suffering from $\mathrm{AD}$ [20]. Several significantly altered metabolites, such as aspartate, glutamate, citrate, and malate, which distinguished $\mathrm{AD}$ from controls were detected. The L-arginine metabolic pathway was identified as highly implicated in the development of $\mathrm{AD}$. In another study, advanced pathway enrichment analysis was applied to detect mutual pathways for AD, Parkinson's disease (PD), and amyotrophic lateral sclerosis [21]. The disease-metabolite-pathway associations pointed out significant involvement of L-arginine metabolism. Similar results indicating the dysregulation of L-arginine metabolism have been acquired in a rodent model of $\mathrm{AD}$ [22].

$\mathrm{L}$-arginine is provided via nutritional intake and via de novo synthesis. The average nutritional L-arginine uptake is approximately $5-6 \mathrm{~g} /$ day [23]. There has been long-standing scientific interest in using the amino acid for the treatment of various diseases. L-arginine supplementation has been shown to stimulate immune responses and promote wound healing [24], particularly in elderly patients [25]. The effect of oral supplementation with a high dose of arginine on the metabolism of elderly people was examined. No adverse effects were observed at a dosage of $17 \mathrm{~g} /$ day of arginine [26]. Moreover, it was demonstrated that arginine supplementation improves performance in elderly male cyclists and enhances their exercise capacity [27]. Other studies show that dietary supplementation with arginine attenuates the increased platelet reactivity in hypercholesterolemic patients [28] and prevents atherogenesis [29].

L-arginine and its derivatives were trialed in patients suffering from various neurological disorders. L-arginine administration within 30 minutes of a stroke has been shown to reduce the severity of stroke-like symptoms [30]. Additionally, $1.6 \mathrm{~g}$ of L-arginine supplemented daily for three months in the diet of patients with senile dementia significantly improved cognitive function [31].

A set of laboratory studies was carried out to decipher the mechanism behind $\mathrm{L}$-arginine neuroprotection. It was verified in various in vitro models that L-arginine enhances cell proliferation and reduces apoptosis [32]. The reverse was also shown: deprivation of L-arginine induces oxidative stress-mediated apoptosis [33]. The antiapoptotic and neuroprotective properties of the amino acid were confirmed in cultured PC-12 cells [34], in motor neurons with excitotoxic injury, and in a transgenic amyotrophic lateral sclerosis mouse model [35].

It is worth mentioning that $\mathrm{L}$-arginine is conveyed from the circulating blood into the brain via $\mathrm{Na}^{+}$-independent cationic amino acid transporter (CAT1), expressed at the blood-brain barrier (BBB) [36]. The influx transport of the amino acid at the rat $\mathrm{BBB}$ is saturable with a Michaelis-Menten constant value of $56 \mu \mathrm{M}$. Notably, the physiological serum concentration of L-arginine in rodents is about $170 \mu \mathrm{M}$; in humans, it is about $100 \mu \mathrm{M}$ [37]. Since L-arginine in 
mammals is derived mostly from renal de novo synthesis and dietary intake, CAT1 at the BBB functions as a sole conduit to the brain [38]. Thus, regardless of its capability to pass the BBB, the capacity of its transporter is restricted [39]. This makes systemic administration inadequate to show all of its possible neurotrophic properties. In order to overcome this limitation, Fonar et al. (2017) bypassed the BBB via chronic intraventricular administration of the amino acid in a mouse model of $\mathrm{AD}$ [34]. The animals treated with L-arginine showed significantly improved spatial memory acquisition.

\section{Nitric Oxide}

L-arginine is a mutual substrate for arginase and nitric oxide synthase (NOS), which produce urea, and nitric oxide (NO) with L-citrulline, respectively [40]. There are three currently known types of NOS: neuronal nitric oxide synthase (NOS1), endothelial nitric oxide synthase (NOS3), and inducible nitric oxide synthase (NOS2) [41]. In addition, there are two distinct types of arginase: arginase1 (ARG1) and arginase 2 (ARG2). The bioavailability of L-arginine is a regulating factor for NO synthesis; thus, its production is seriously dependent upon arginase activity, which easily depletes the substrate [42].

$\mathrm{NO}$ is a signaling molecule involved in the regulation of the cardiovascular, nervous, and immune systems [41]. Moreover, reduced bioavailability of NO was shown to be involved in various vascular disorders, including hypertension, atherosclerosis, diabetes, and ischemia-reperfusion injury [43]. Consequently, it was hypothesized that anomalous NO signaling contributes to the pathogenesis of various neurodegenerative pathologies such as stroke/excitotoxicity, $\mathrm{AD}$, multiple sclerosis (MS), and PD [44].

There are data showing a severe reduction of NOS activity in AD brains, with a decrease in the levels of NOS1 and NOS3 proteins [45]. Venturini et al. (2012) demonstrated that amyloid peptide strongly inhibits the NOS1 and NOS3 activity in cell-free and cellular systems; this provides a novel, intriguing molecular mechanism for AD development [46].

A growing body of evidence indicates that NO possesses neuroprotective properties. First, it triggers vasodilation and increases blood supply to neurons, which reduces their susceptibility to oxidative stress [47]. Moreover, NO regulates $\mathrm{Ca}^{2+}$ influx into the neurons via inhibition of NMDA receptors at glutamatergic synapses, protecting the cells from overstimulation and, subsequently, excitotoxicity [48]. Additionally, L-citrulline, which is a byproduct of the reaction and is catalyzed by NOS, was shown to possess neuroprotective properties as well [49].

In order to explore the potential role of $\mathrm{NO}$ in the development of $\mathrm{AD}$, $\mathrm{APP} / \mathrm{NOS}^{-1-}$ mice were designed [50]. The mice express the human Swedish mutation (APPSw; $\operatorname{Tg} 2576$ ) on a homozygous mouse NOS2 knockout background and exhibit the behavioral deficits and biochemical hallmarks of AD. Working with this model of AD, Kan et al. (2015) demonstrated that ARG1 is 
highly expressed in regions of $A \beta$ accumulation [51]. It was proven that pharmacologic disruption of the arginine utilization pathway by irreversible inhibition of ornithine decarboxylase (ODC) with $\alpha$-difluoromethylornithine (DFMO) protects the mice from AD-like pathology and reverses memory loss. The authors suggest that $\mathrm{L}$-arginine depletion is responsible for neuronal cell death and cognitive deficits in the course of $\mathrm{AD}$ development.Another knockout $\left(\mathrm{NOS}^{-{ }^{--}}\right.$) mouse model was shown to develop Alzheimer's-like pathology [52]. Moreover, a negative correlation between capillary-expressed NOS3 and Alzheimer's lesion burden was reported [53].

Recent experimental data provide evidence that L-arginine administration restores NO synthesis, which leads to improvement of vascular function in cardiovascular disorders [29] [54] [55]. These findings prove the crucial role of L-arginine bioavailability in vascular pathologies and neurodegenerative diseases. Even though the particular causes of the reduction in L-arginine availability are still unspecified, emerging evidence suggests that catabolism of L-arginine by arginase is involved.

\section{Arginase}

Arginase is a manganese metalloenzyme that catalyzes the hydrolysis of L-arginine to L-ornithine and urea. Two distinct genetic isoforms of arginase have been identified that share approximately $60 \%$ amino acid sequence homology [56]. The arginases are homotrimericmetalloenzymes stabilized in conformation by two $\mathrm{Mn}^{2+}$ ions per monomeric structure [57].

Arginases are ubiquitous in early life-forms and currently existing phyla [58]. Plants, bacteria, and yeasts have a single form of arginase localized in mitochondria (ARG2). Vertebrates process nitrogen by another cytosolic isoform of arginase (ARG1) [59]. The isoenzymes demonstrate distinctive cell and tissue patterns of distribution. In humans, ARG1 is generally presented as a cytosolic enzyme of the liver and is also expressed in various regions of the brain. ARG2, described in the literature as a kidney-type arginase, is ubiquitously expressed at a low level within the mitochondria of various organs [60].

The primary metabolic function of arginases in ureotelic animals is the removal of excess ammonia via the urea cycle. This is the central role of ARG1 in the hepatic tissue [61]. The presence of both ARG1 and ARG2 in the brain, especially in hippocampal neurons, has been confirmed by immunocytochemical analysis of rat [62] and mouse brain sections [63]. Moreover, it has been established that ARG2 is the predominant isoform of the human frontal cortex [64]. Consequently, it has been suggested that arginases of the brain do not function in the same manner as in the liver, because of the relative deficiency of other urea cycle-critical enzymes in the brain tissue. It has been reported that at least two critical for the urea cycle enzymes, ornithine transcarbamylase (OTC) and carbamoyl phosphate synthetase 1 (CPS1), are present in very low concentrations in the mammal brain [65]. Moreover, it has been established that arginase 
activity in the rodent brain comprises less than $0.1 \%$ of the activity in the liver [66]. Of note, the typical arginase activity for the liver is $14 \mu \mathrm{M}$ of urea produced per min per mg of protein; however, for brain tissue, it is only $0.0135 \mu \mathrm{M}$ of urea $\mathrm{min} / \mathrm{mg}[61]$.

It is worth mentioning that the expression of two isoforms of arginase can be impelled in different tissues via exposure to a variety of cytokines and catecholamines [67]. ARG2 in endothelial cells is inducible by many stimuli, including lipopolysaccharide (LPS), tumor necrosis factor alpha (TNF $\alpha$ ), oxidized Low-Density Lipoprotein (LDL), and hypoxia [68]. Moreover, it has been demonstrated that activation of ARG2 is associated with its translocation from the mitochondria to the cytosol [69]. Data acquired in our lab confirm the expression of mitochondrial ARG2 in the cytoplasm of the hippocampal neurons of the AD mouse model (Figure 1) [63]. It is noteworthy that arginases are present in various extracellular fluids and capable of hydrolyzing L-arginine in plasma, saliva, etc. [70].

Even though arginase has been shown to be a neuroprotective factor and to support neuroregeneration in vitro [71] [72], recent studies suggest that arginase plays a role in the pathogenesis of $\mathrm{AD}$ and other metabolic diseases [73]. First, significantly decreased levels of L-arginine in the cortices of AD patients have been observed [74]. Additionally, the activity and expression level of NOS and arginase are meaningfully altered in $\mathrm{AD}$ brains in a region-specific manner. Namely, the activity of arginase is significantly higher and that of NOS is lower in the hippocampi of AD patients [45].

There are recent data showing that the postmortem brains of $\mathrm{AD}$ patients contain significantly higher concentrations of urea, which is a product of the reaction catalyzed by arginase, compared to the control group [75]. Likewise, other neurodegenerative diseases were specified as having high brain urea concentrations and misbalanced expression of the related genes. For example, it has been reported that the brains of patients suffering from Huntington's disease (HD) contain about threefold more urea compared to healthy controls [76]. This finding has been verified in a transgenic sheep model of HD [77]. Consequently, a hypothesis was proposed that links the build-up of urea in the brain to toxic levels, causing brain damage and, finally, dementia [77].

Additionally, there are indications that the expression of the ARG2 gene is significantly higher in AD brains compared to control brains [78]. Consequently, a potential association of the ARG2 gene with the risk of developing AD has been hypothesized. Furthermore, it has been demonstrated that ARG2 deficiency reduces the rate of hyperoxia-mediated retinal neurodegeneration [79], suggesting the involvement of arginase in the pathogenesis of neuronal degeneration via excessive activation of the excitotoxic NMDA receptors [80]. At the molecular level, a mutual positive regulation has been demonstrated between ribosomal protein S6 kinase beta-1 (S6K1) and ARG2 in endothelial inflammation processes and aging [81]. It has therefore been suggested that ARG2 and mecha- 
nistic target of rapamycin (mTOR-S6K1) pathways play an important role in promoting oxidative stress, inflammation, senescence, and death, which eventually leads to metabolic disorders [82]. Therefore, targeting ARG2 has recently been proposed as a means of treatment for decelerating age-related diseases [83].

Moreover, upregulation of arginase has been associated with other diseases of the neural system, such as PD, multiple sclerosis, stroke, traumatic brain injury, and several retinal diseases [59] [84]. Remarkably, L-ornithine levels are decreased in $\mathrm{AD}$ brains [8]. L-ornithine is the product of the reaction catalyzed by arginase, which is upregulated in AD. However, ODC and OTC are upregulated in $\mathrm{AD}$ brains as well. These enzymes easily deplete the mutual substrate, which leads to relative L-ornithine deficiency [85].

Inoue et al. (2013) studied changes in the concentration and localization of molecules having a low molecular weight. To do so, they utilized a postmortem human brain metabolic profiling methodology, using ultra-performance liquid chromatography coupled with electrospray time-of-flight mass spectrometry analysis [86]. The multivariate statistical analysis of metabolites in brain tissues link the pathological changes that occur in $\mathrm{AD}$ brains with the deviated metabolic pathway of polyamines. The researchers found a significant increase in downstream metabolites of ornithine, potentially implicating ODC activity in AD pathology (Figure 1). Another study confirms significantly $(\mathrm{p}<0.02)$ increased levels of spermidine in the brains of $\mathrm{AD}$ patients [87].

The empirical data collected in recent years indicate a complex anomaly of $\mathrm{L}$-arginine metabolism in the brains of $\mathrm{AD}$ patients. The findings point to new rational therapeutic avenues leading to the amelioration of symptoms and halting the progression of $\mathrm{AD}$. In this context, pharmacological fine-tuning of arginase activity appears to be a reasonable approach.

\section{Arginase Inhibitors}

Since the expression and activity of arginases have been shown to be upregulated in various diseases, including atherosclerosis, diabetes mellitus, and $\mathrm{AD}$, specific inhibitors have been designed to be clinically investigated.

There are several highly potent and specific inhibitors now available to probe arginase function and modulate the balance between NOS and arginase pathways. Some of the substances are rationally synthesized; some are natural, plant-derived compounds with high arginase inhibitory competence, such as piceatannol-3'-O- $\beta$-d-glucopyranoside. All of these small molecules represent a promising cluster of medicines for the treatment of metabolic and cardiovascular diseases [73]. An incomplete list of these chemicals is presented in Table 2. Unfortunately, several effective synthesized arginase inhibitors are relatively toxic substances, which limit their clinical application [89]. However, several products of L-arginine metabolism possess arginase-inhibiting properties and represent a promising cluster of substances. For example, L-ornithine and L-citrulline have been shown to inhibit arginase efficiently. L-citrulline has been 
Table 2. Arginase inhibitors.

\begin{tabular}{|c|c|}
\hline Inhibitor & $\begin{array}{l}\text { Description and type of inhibition } \\
\text { (with respect to L-arginine) }\end{array}$ \\
\hline $\begin{array}{l}\text { 2(S)-Amino-6-boronohexanoic acid } \\
\text { hydrochloride hydrochloride }(\mathrm{ABH})\end{array}$ & $\begin{array}{l}\text { A potent, specific, } \\
\text { competitive arginase inhibitor }\end{array}$ \\
\hline $\begin{array}{l}\text { (2R)-2-amino-3-(2-boronoethylsulfanyl)propan } \\
\text { oic acid (BEC) hydrochloride }\end{array}$ & $\begin{array}{l}\text { A boronic acid-based arginine analog, which } \\
\text { acts as a selective, slow-binding, reversible, } \\
\text { competitive arginase inhibitor }\end{array}$ \\
\hline NG-Hydroxy-L-arginine (NOHA) acetate salt & $\begin{array}{l}\text { Intermediate in the conversion of arginine to } \\
\mathrm{NO} \text { and citrulline by NO synthase. Acts as } \\
\text { reversible competitivearginase inhibitor }\end{array}$ \\
\hline Nor-NOHA diacetate salt & $\begin{array}{c}\text { More potent than a NOHA inhibitor, } \\
\text { which exhibits } 10 \text {-fold selectivity for } \\
\text { human ARG2 over ARG1 }\end{array}$ \\
\hline Chloroquine & Competitive arginase inhibitor \\
\hline Piceatannol-3'-O- $\beta$-d-glucopyranoside (PG) & Competitive arginase inhibitor \\
\hline L-ornithine & Competitive arginase inhibitor \\
\hline L-norvaline & Non-competitive inhibitor \\
\hline
\end{tabular}

proven to be an allosteric modulator of arginase activity [90]. L-ornithine inhibits arginase by competing with L-arginine on the active sites of arginase [91]. Another non-proteinogenic amino acid, L-norvaline, demonstrates potency similar to that of L-ornithine; however, since it acts via a non-competitive inhibition mechanism [92] [93], its application is very attractive. The substance has been successfully applied already in rats with streptozotocin-induced diabetes [94], [95].

\section{Arginase Inhibition and AD}

The idea to block L-arginine depletion and reverse its deprivation, thereby halting memory loss and reducing other $\mathrm{AD}$ symptoms, has been previously explored. In the abovementioned study, Kan et al., demonstrated that ARG1 is highly expressed in regions of $\mathrm{A} \beta$ deposition [51]. The authors proved that pharmacologic disruption of the arginine utilization pathway by irreversible inhibition of ODC with DFMO protected mice from AD-like pathology and reversed memory loss. The authors suggested that L-arginine depletion is responsible for neuronal cell death and cognitive deficits in the course of AD development. It is worth mentioning that DFMO is a relatively toxic and irreversible inhibitor of ODC. In order to avoid undesirable side effects, it was provided together with putrescine in a mouse model of $\mathrm{AD}$.

In our current research (which is ongoing in our lab), we inhibit arginase using L-norvaline, which acts via a negative feedback inhibition mechanism [63]. Accordingly, we do not administer polyamines to the animals. Instead, we provide the mice with L-norvaline dissolved in water in their home cages; this is a much less invasive methodology compared to the forced gavage feeding used by 


\section{Kan et al.}

A report was recently published with results from a single case-study in which DFMO was administered, for the first time, in an attempt to slow the progression of $\mathrm{AD}$ [96]. A 74-year-old woman with multidomain amnestic mild cognitive impairment, who was unable to tolerate an acetylcholinesterase inhibitor, participated in the trial. The patient, with a 5-year history of cognitive decline, was placed on DFMO (500 mg twice a day) for 12 months. The patient did not react to the treatment. Moreover, she continued to experience cognitive decline during the course of the trial, including progressive worsening of orientation, social functioning, and the ability to engage in the regular activities of daily living. The objective measures of episodic memory and executive functioning also demonstrated progressive deterioration. Florbetapir positron-emission tomography (PET) imaging revealed elevated total neocortical standardized uptake values, both at baseline and at 12 months. This shows that application of DFMO was not effective in halting either amyloidosis or cognitive decline.

Of note, DFMO is a potent, irreversible "suicide" ODC inhibitor [97]. Its ability to inhibit arginine is very limited. Using in vitro experiments, Selamnia et al. (1998) established that DFMO is a weak arginase inhibitor with $K \mathbf{i}=3.9 \mathrm{mM}$ [98]. Consequently, relatively high concentrations of the substance are required to inhibit arginase activity. Thus, there are possible nonspecific effects of its application as an arginase inhibitor. Moreover, the age of the patient and the development of pathology were very advanced to block amyloidosis and improve cognitive function. In our opinion, arginase inhibitors should be trialed on autosomal gene carriers for early-onset $\mathrm{AD}$, who are in the preclinical disease stages.

According to our hypothesis, upregulation of arginase activity and consequent L-arginine and NO deficiency in the brain lead to the manifestation of AD pathology. We therefore targeted arginase and not ODC to ameliorate the symptoms of the disease. We used a triple-transgenic mouse model of $\mathrm{AD}$ (3xTg-AD), harboring the PS1(M146V), APP(Swe), and tau(P301L) transgenes. The mice exhibit synaptic deficiency with both plaque and tangle pathology [99].

Animals treated with L-norvaline for two months did not display short- or long-term memory deficiency compared to the wild-type (WT) mice. Moreover, the observed cognitive effect was associated with significantly reduced $\beta$-amyloidosis and microgliosis. Likewise, the treatment reversed dendritic spine deficiency in the cortices and hippocampi and amplified the expression levels of pre- and postsynaptic proteins.

It has previously been demonstrated that L-norvaline amplifies the rate of $\mathrm{NO}$ production and reduces urea production [100]. L-norvaline has been used successfully to treat artificial metabolic syndrome in a rat model [101]. Moreover, there are reports that L-norvaline inhibits S6K1 as well and possesses anti-inflammatory properties [102]. We showed that L-norvaline treatment leads to a $53 \%$ reduction of the levels of RAC-alpha protein-serine/threonine kinase 
(Akt1) in the brain. This kinase is located upstream to mTOR and S6K1; therefore, downregulation of Akt1 can negatively influence S6K1 activity. Upregulation of the mTOR-signaling pathway was shown to play an essential role in the pathogenesis of $\mathrm{AD}$ [103]. Accordingly, mTOR-signaling inhibition is a novel therapeutic target for AD [104].

It is noteworthy that L-norvaline is competent to be a substrate for branchedchain amino acid aminotransferase (BCAT) [105]. The branched-chain amino acids include leucine, isoleucine, and valine. There are data showing that the levels of valine are significantly reduced in the plasma of AD patients [8]. BCAT catalyzes the conversion of branched-chain amino acids and $\alpha$-ketoglutarate into branched-chain $\alpha$-keto acids and glutamate. Therefore, BCAT activity is a critical factor in the regulation of glutamine and glutamate production.

Glutamine supplementation has been shown to moderate tau phosphorylation and reduce inflammation in a mouse model of $\mathrm{AD}$ [106]. It is worth mentioning that glutamine levels tend to decline in the brains of $\mathrm{AD}$ patients [107], and they are significantly decreased in the temporal lobe of the AD patients. Sweat et al. (2004) proved via IHC analysis of the rodent brains that BCAT is strongly expressed in the mossy fiber pathway of the hippocampus and dentate gyrus, where it is localized at axons and nerve terminals [108]. Moreover, Li et al. (2018) showed that the defect of the branched-chain amino acid metabolism promotes the development of AD [109]. Additionally, they demonstrated that the expression of the BCAT1 isoform is significantly downregulated in the brain tissues of diabetic, aged, and $\mathrm{AD}$ mice.

We provided evidence that chronic L-norvaline administration leads to a significant increase in expression levels of vesicular glutamate transporter 3 (by $458 \%$ ) and vesicular glutamate transporter 1 (by 349\%) in the hippocampi of AD mouse models [63]. These findings suggest elevation in the levels of glutamate produced by BCAT from L-norvaline in the brain. Moreover, superoxide dismutase $[\mathrm{Cu}-\mathrm{Zn}$ ] (SOD) levels were elevated by $19 \%$ in the brains of the treated animals. These enzymes play a critical role in cellular response to oxygen-containing compounds. It was convincingly demonstrated in a rat model with NMDA excitotoxic lesions that overexpression of superoxide dismutase [Cu-Zn] leads to neuroprotection and improved functional outcome [110].

Additionally, we observed significantly elevated (by $24 \%$ ) levels of phosphatidylinositol 3-kinase regulatory subunit alpha. Yu et al. verified that this kinase plays a role in protection against $\mathrm{H}_{2} \mathrm{O}_{2}$-induced neuron degeneration [111]. Remarkably, the levels of reelin signal transducer, homolog 1 (DAB1) increased significantly (by 37\%) following the treatment. The reelin pathway has been previously identified as protective in $\mathrm{AD}$, and high $\mathrm{DAB} 1 \mathrm{mRNA}$ expression has been shown to correlate positively with AD protection [112]. Moreover, cytochrome $\mathrm{c}$ oxidase subunit 4 , which is essential for the assembly and respiratory function of mitochondria [113], was elevated by $31 \%$. Earlier, we mentioned cytochrome $\mathrm{c}$ oxidase deficiency as a characteristic metabolic dysfunction detected 
in $\mathrm{AD}$ brains; therefore, increase in the levels of this protein, which is critical for electron transfer, may be partially responsible for the strong behavioral phenotype following L-norvaline treatment.

\section{Conclusion}

In conclusion, we stress the manifold benefits of L-norvaline application in $\mathrm{AD}$ and list its diverse modes of activity. Namely, L-norvaline is an arginase inhibitor and a potent inhibitor of the mTOR pathway. Additionally, the amino acid is a substrate for BCAT; thus, the application of L-norvaline leads to an increase in glutamate levels at the synapses. Moreover, L-norvaline activates pathways involved in cellular response to oxygen-containing compounds. All the mentioned modes of L-norvaline activity have the potential to improve the symptoms of $\mathrm{AD}$ and even interfere with its pathogenesis (Figure 2). We have shown that L-norvaline represents a promising neuroprotective molecule and possesses multiple potential biological qualities that might be tailored for the treatment of

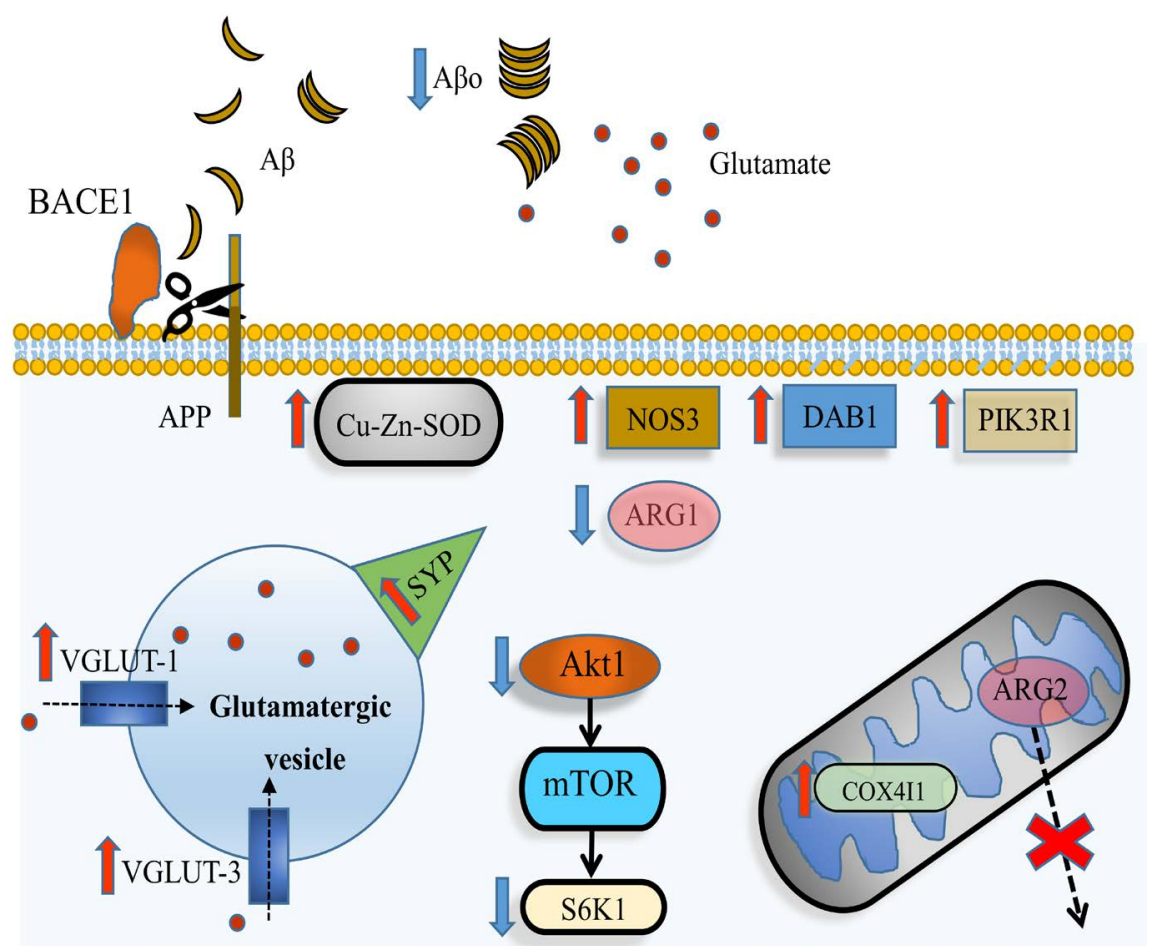

Figure 2. Metabolic effects of L-norvaline in the 3xTg-AD mouse brain. L-norvaline treatment leads to a reduction of the quantities of $\mathrm{A} \beta$ fibrils and prefibrillar oligomers $(\mathrm{A} \beta \mathrm{O})$, an increase in the expression levels of vesicular glutamate transporter 1 and 3 (VGLUT-1 and VGLUT-3, respectively), synaptophysin (SYP), nitric oxide synthase 3 (NOS3), superoxide dismutase [Cu-Zn] (SOD), disabled-1 (Dab1) protein, phosphatidylinositol 3-kinase regulatory subunit alpha (PIK3R1), and cytochrome c oxidase subunit 4 (COX4I1). At the same time, L-norvaline reduces the levels of arginase 1 (ARG1) and arginase 2 (ARG2), RAC-alpha serine/threonine-protein kinase (Akt1), and inhibits ribosomal protein S6 kinase beta-1 (S6K1). Moreover, its application prevents translocation of ARG2 from mitochondria to the cytoplasm. Red arrows represent elevated levels of the proteins; blue arrows designate reduction compared to the vehicle-treated controls. 
a range of neurodegenerative disorders. Additional research is required to discover the optimal concentration of the substance for providing the best neuroprotection. Likewise, other AD models can be utilized to validate the results, elucidate, and confirm the precise neuroprotective mechanisms.

\section{Conflicts of Interest}

The authors declare no conflicts of interest regarding the publication of this paper.

\section{References}

[1] Prince, M., Bryce, R., Albanese, E., Wimo, A., Ribeiro, W. and Ferri, C.P. (2013) The Global Prevalence of Dementia: A Systematic Review and Metaanalysis. Alzheimer's Dement, 9, 63-75. https://doi.org/10.1016/j.jalz.2012.11.007

[2] Magalingam, K.B., Radhakrishnan, A., Ping, N.S. and Haleagrahara, N. (2018) Current Concepts of Neurodegenerative Mechanisms in Alzheimer's Disease. BioMed Research International, 2018, Article ID: 3740461. https://doi.org/10.1155/2018/3740461

[3] Cai, H., Cong, W., Ji, S., Rothman, S., Maudsley, S. and Martin, B. (2012) Metabolic Dysfunction in Alzheimer's Disease and Related Neurodegenerative Disorders. Current Alzheimer Research, 9, 5-17. https://doi.org/10.2174/156720512799015064

[4] Luchsinger, J.A. (2008) Adiposity, Hyperinsulinemia, Diabetes and Alzheimer's Disease. An Epidemiological Perspective. European Journal of Pharmacology, 585, 119-129. https://doi.org/10.1016/j.ejphar.2008.02.048

[5] Alford, S., Patel, D., Perakakis, N. and Mantzoros, C.S. (2018) Obesity as a Risk Factor for Alzheimer's Disease: Weighing the Evidence. Obesity Reviews, 19, 269-280. https://doi.org/10.1111/obr.12629

[6] Lathe, R., Sapronova, A. and Kotelevtsev, Y. (2014) Atherosclerosis and Alzheimer-Diseases with a Common Cause? Inflammation, Oxysterols, Vasculature. BMC Geriatrics, 14, 36. https://doi.org/10.1186/1471-2318-14-36

[7] Gupta, A. and Iadecola, C. (2015) Impaired A $\beta$ Clearance: A Potential Link between Atherosclerosis and Alzheimer's Disease. Frontiers in Aging Neuroscience, 7, 115.

[8] González-Domínguez, R., García-Barrera, T. and Gómez-Ariza, J.L. (2015) Metabolite Profiling for the Identification of Altered Metabolic Pathways in Alzheimer's Disease. Journal of Pharmaceutical and Biomedical Analysis, 107, 75-81.

[9] Ríos, J.A., Cisternas, P., Arrese, M., Barja, S. and Inestrosa, N.C. (2014) Is Alzheimer's Disease Related to Metabolic Syndrome? A Wnt Signaling Conundrum. Progress in Neurobiology, 121, 125-146. https://doi.org/10.1016/j.pneurobio.2014.07.004

[10] Sonntag, K.C., Ryu, W.I., Amirault, K.M., Healy, R.A., Siegel, A.J., McPhie, D.L., Forester, B. and Cohen, B.M. (2017) Late-Onset Alzheimer's Disease Is Associated with Inherent Changes in Bioenergetics Profiles. Scientific Reports, 7, Article No. 14038. https://doi.org/10.1038/s41598-017-14420-x

[11] Wilkins, J.M. and Trushina, E. (2018) Application of Metabolomics in Alzheimer's Disease. Frontiers in Neurology, 8, 1-20. https://doi.org/10.3389/fneur.2017.00719

[12] Eckert, A., Schmitt, K. and Götz, J. (2011) Mitochondrial Dysfunction-The Beginning of the End in Alzheimer's Disease? Separate and Synergistic Modes of Tau and Amyloid- $\beta$ Toxicity. Alzheimer's Research \& Therapy, 3, 15. 
[13] Casley, C.S., Canevari, L., Land, J.M., Clark, J.B. and Sharpe, M.A. (2002) Beta-Amyloid Inhibits Integrated Mitochondrial Respiration and Key Enzyme Activities. Journal of Neurochemistry, 80, 91-100.

[14] Hernandez-Zimbron, L.F., Luna-Muñoz, J., Mena, R., Vazquez-Ramirez, R., Kubli-Garfias, C., Cribbs, D.H., Manoutcharian, K. and Gevorkian, G. (2012) Amyloid- $\beta$ Peptide Binds to Cytochrome C Oxidase Subunit 1. PLoS ONE, 7, e42344. https://doi.org/10.1371/journal.pone.0042344

[15] van Dyck, C.H. (2018) Anti-Amyloid- $\beta$ Monoclonal Antibodies for Alzheimer's Disease: Pitfalls and Promise. Biological Psychiatry, 83, 311-319. https://doi.org/10.1016/j.biopsych.2017.08.010

[16] Palmer, A.M. (2011) Neuroprotective Therapeutics for Alzheimer's Disease: Progress and Prospects. Trends in Pharmacological Sciences, 32, 141-147. https://doi.org/10.1016/j.tips.2010.12.007

[17] Gejl, M., Gjedde, A., Egefjord, L., Møller, A., Hansen, S.B., Vang, K., Rodell, A., Brændgaard, H., Gottrup, H., Schacht, A., Møller, N., Brock, B. and Rungby, J. (2016) In Alzheimer's Disease, 6-Month Treatment with GLP-1 Analog Prevents Decline of Brain Glucose Metabolism: Randomized, Placebo-Controlled, Double-Blind Clinical Trial. Frontiers in Aging Neuroscience, 8, 108.

[18] Cederbaum, S.D., Yu, H., Grody, W.W., Kern, R.M., Yoo, P. and Iyer, R.K. (2004) Arginases I and II: Do Their Functions Overlap? Molecular Genetics and Metabolism, 81, S38-S44.

[19] Wu, G. and Morris, S.M. (1998) Arginine Metabolism: Nitric Oxide and Beyond. Biochemical Journal, 336, 1-17.

[20] Paglia, G., Stocchero, M., Cacciatore, S., Lai, S., Angel, P., Alam, M.T., Keller, M., Ralser, M. and Astarita, G. (2016) Unbiased Metabolomic Investigation of Alzheimer's Disease Brain Points to Dysregulation of Mitochondrial Aspartate Metabolism. Journal of Proteome Research, 15, 608-618. https://doi.org/10.1021/acs.jproteome.5b01020

[21] Kori, M., Aydın, B., Unal, S., Arga, K.Y. and Kazan, D. (2016) Metabolic Biomarkers and Neurodegeneration: A Pathway Enrichment Analysis of Alzheimer's Disease, Parkinson's Disease, and Amyotrophic Lateral Sclerosis. OMICS, 20, 645-661.

[22] Yu, J., Kong, L., Zhang, A., Han, Y., Liu, Z., Sun, H., Liu, L. and Wang, X. (2017) High-Throughput Metabolomics for Discovering Potential Metabolite Biomarkers and Metabolic Mechanism from the APPswe/PS1dE9 Transgenic Model of Alzheimer's Disease. Journal of Proteome Research, 16, 3219-3228. https://doi.org/10.1021/acs.jproteome.7b00206

[23] Witte, M.B. and Barbul, A. (2003) Arginine Physiology and Its Implication for Wound Healing. Wound Repair and Regeneration, 11, 419-423. https://doi.org/10.1046/j.1524-475X.2003.11605.x

[24] Barbul, A., Lazarou, S.A., Efron, D.T., Wasserkrug, H.L. and Efron, G. (1990) Arginine Enhances Wound Healing and Lymphocyte Immune Response in Humans. Surgery, 108, 336-337.

[25] Kirk, S.J., Hurson, M., Regan, M.C., Holt, D.R., Wasserkrug, H.L. and Barbul A. (1993) Arginine Stimulates Wound Healing and Immune Function in Elderly Human Beings. Surgery, 114, 155-159.

[26] Hurson, M., Regan, M., Kirk, S., Wasserkrug, H. and Barbul, A. (1995) Metabolic Effects of Arginine in a Healthy Elderly Population. Journal of Parenteral and Enteral Nutrition, 19, 227-230. https://doi.org/10.1177/0148607195019003227

[27] Chen, S., Kim, W., Henning, S.M., Carpenter, C.L. and Li, Z. (2010) Arginine and 
Antioxidant Supplement on Performance in Elderly Male Cyclists: A Randomized Controlled Trial. Journal of the International Society of Sports Nutrition, 7, 13. https://doi.org/10.1186/1550-2783-7-13

[28] Wolf, A., Zalpour, C., Theilmeier, G., Wang, B.Y., Ma, A., Anderson, B., Tsao, P.S. and Cooke, J.P. (1997) Dietary L-Arginine Supplementation Normalizes Platelet Aggregation in Hypercholesterolemic Humans. Journal of the American College of Cardiology, 29, 479-485. https://doi.org/10.1016/S0735-1097(97)00523-8

[29] Cooke, J.P., Singer, A.H., Tsao, P., Zera, P., Rowan, R.A. and Billingham, M.E. (1992) Antiatherogenic Effects of L-Arginine in the Hypercholesterolemic Rabbit. Journal of Clinical Investigation, 90, 1168-1172. https://doi.org/10.1172/JCI115937

[30] Koga, Y., Akita, Y., Nishioka, J., Yatsuga, S., Povalko, N., Tanabe, Y., Fujimoto, S. and Matsuishi, T. (2005) L-Arginine Improves the Symptoms of Strokelike Episodes in MELAS. Neurology, 64, 710-712. https://doi.org/10.1212/01.WNL.0000151976.60624.01

[31] Ohtsuka, Y. and Nakaya, J. (2000) Effect of Oral Administration of L-Arginine on Senile Dementia. The American Journal of Medicine, 108, 439. https://doi.org/10.1016/S0002-9343(99)00396-4

[32] Greene, J.M., Feugang, J.M., Pfeiffer, K.E., Stokes, J.V., Bowers, S.D. and Ryan, P.L. (2013) L-Arginine Enhances Cell Proliferation and Reduces Apoptosis in Human Endometrial RL95-2 Cells. Reproductive Biology and Endocrinology, 11, 15.

[33] Mandal, A., Das, S., Roy, S., Ghosh, A.K., Sardar, A.H., Verma, S., Saini, S., Singh, R., Abhishek, K., Kumar, A., Mandal, C. and Das, P. (2016) Deprivation of L-Arginine Induces Oxidative Stress Mediated Apoptosis in Leishmania donovani Promastigotes: Contribution of the Polyamine Pathway. PLOS Neglected Tropical Diseases, 10, e0004373.

[34] Fonar, G., Polis, B., Meirson, T., Maltsev, A. and Samson, A.O. (2018) Intracerebroventricular Administration of L-Arginine Improves Spatial Memory Acquisition in Triple Transgenic Mice via Reduction of Oxidative Stress and Apoptosis. Translational Neuroscience, 9, 43-53. https://doi.org/10.1515/tnsci-2018-0009

[35] Lee, J., Ryu, H. and Kowall, N.W. (2009) Motor Neuronal Protection by l-Arginine Prolongs Survival of Mutant SOD1 (G93A) ALS Mice. Biochemical and Biophysical Research Communications, 384, 524-529.

[36] O’Kane, R.L., Viña, J.R., Simpson, I., Zaragozá, R., Mokashi, A. and Hawkins, R.A. (2006) Cationic Amino Acid Transport across the Blood-Brain Barrier Is Mediated Exclusively by System $\mathrm{y}^{+}$. American Journal of Physiology-Endocrinology and Metabolism, 291, E412-E419. https://doi.org/10.1152/ajpendo.00007.2006

[37] Stoll, J., Wadhwani, K.C. and Smith, Q.R. (1993) Identification of the Cationic Amino Acid Transporter (System $\mathrm{y}^{+}$) of the Rat Blood-Brain Barrier. Journal of Neurochemistry, 60, 1956-1959. https://doi.org/10.1111/j.1471-4159.1993.tb13428.x

[38] Tachikawa, M. and Hosoya, K. (2011) Transport Characteristics of Guanidino Compounds at the Blood-Brain Barrier and Blood-Cerebrospinal Fluid Barrier: Relevance to Neural Disorders. Fluids and Barriers of the CNS, 8, 13. https://doi.org/10.1186/2045-8118-8-13

[39] Shin, W.-W., Fong, W.-F., Pang, S.-F. and Wong, P.C. (1985) Limited Blood-Brain Barrier Transport of Polyamines. Journal of Neurochemistry, 44, 1056-1059. https://doi.org/10.1111/j.1471-4159.1985.tb08724.x

[40] Nelson, D.L. and Cox, M.M. (2004) Lehninger Principles of Biochemistry. W.H. Freeman, 1120 . 
[41] Förstermann, U. and Sessa, W.C. (2012) Nitric Oxide Synthases: Regulation and Function. European Heart Journal, 33, 829-837.

[42] Balez, R. and Ooi, L. (2016) Getting to NO Alzheimer's Disease: Neuroprotection versus Neurotoxicity Mediated by Nitric Oxide. Oxidative Medicine and Cellular Longevity, 2016, Article ID: 3806157. https://doi.org/10.1155/2016/3806157

[43] Lefer, A.M. and Lefer, D.J. (1996) The Role of Nitric Oxide and Cell Adhesion Molecules on the Microcirculation in Ischaemia-Reperfusion. Cardiovascular Research, 32, 743-751.

[44] Steinert, J.R., Chernova, T. and Forsythe, I.D. (2010) Nitric Oxide Signaling in Brain Function, Dysfunction, and Dementia. Neuroscientist, 16, 435-452. https://doi.org/10.1177/1073858410366481

[45] Liu, P., Fleete, M.S., Jing, Y., Collie, N.D., Curtis, M.A., Waldvogel, H.J., Faull, R.L.M., Abraham, W.C. and Zhang, H. (2014) Altered Arginine Metabolism in Alzheimer's Disease Brains. Neurobiology of Aging, 35, 1992-2003. https://doi.org/10.1016/j.neurobiolaging.2014.03.013

[46] Venturini, G., Colasanti, M., Persichini, T., Fioravanti, E., Ascenzi, P., Palomba, L., Cantoni, O. and Musci, G. (2002) Beta-Amyloid Inhibits NOS Activity by Subtracting NADPH Availability. The FASEB Journal, 16, 1970-1972. https://doi.org/10.1096/fj.02-0186fje

[47] Durante, W., Johnson, F.K. and Johnson, R.A. (2007) Arginase: A Critical Regulator of Nitric Oxide Synthesis and Vascular Function. Clinical and Experimental Pharmacology and Physiology, 34, 906-911. https://doi.org/10.1111/j.1440-1681.2007.04638.x

[48] Ditlevsen, D.K., Køhler, L.B., Berezin, V. and Bock, E. (2007) Cyclic Guanosine Monophosphate Signalling Pathway Plays a Role in Neural Cell Adhesion Molecule-Mediated Neurite Outgrowth and Survival. Journal of Neuroscience Research, 85, 703-711. https://doi.org/10.1002/jnr.21175

[49] Yabuki, Y., Shioda, N., Yamamoto, Y., Shigano, M., Kumagai, K., Morita, M. and Fukunaga, K. (2013) Oral 1-Citrulline Administration Improves Memory Deficits Following Transient Brain Ischemia through Cerebrovascular Protection. Brain Research, 1520, 157-167. https://doi.org/10.1016/j.brainres.2013.05.011

[50] Wilcock, D.M., Lewis, M.R., Van Nostrand, W.E., Davis, J., Lou Previti, M., Gharkholonarehe, N., Vitek, M.P. and Colton, C.A. (2008) Progression of Amyloid Pathology to Alzheimer's Disease Pathology in an Amyloid Precursor Protein Transgenic Mouse Model by Removal of Nitric Oxide Synthase 2. Journal of Neuroscience, 28, 1537-1545. https://doi.org/10.1523/JNEUROSCI.5066-07.2008

[51] Kan, M.J., Lee, J.E., Wilson, J.G., Everhart, A.L., Brown, C.M., Hoofnagle, A.N., Jansen, M., Vitek, M.P., Gunn, M.D. and Colton, C.A. (2015) Arginine Deprivation and Immune Suppression in a Mouse Model of Alzheimer's Disease. Journal of Neuroscience, 35, 5969-5982. https://doi.org/10.1523/JNEUROSCI.4668-14.2015

[52] Austin, S.A., Santhanam, A.V., Hinton, D.J., Choi, D.-S. and Katusic, Z.S. (2013) Endothelial Nitric Oxide Deficiency Promotes Alzheimer's Disease Pathology. Journal of Neurochemistry, 127, 691-700. https://doi.org/10.1111/jnc.12334

[53] Jeynes, B. and Provias, J. (2009) Significant Negative Correlations between Capillary Expressed eNOS and Alzheimer Lesion Burden. Neuroscience Letters, 463, 244-248. https://doi.org/10.1016/j.neulet.2009.07.091

[54] Drexler, H., Zeiher, A.M., Meinzer, K. and Just, H. (1991) Correction of Endothelial Dysfunction in Coronary Microcirculation of Hypercholesterolaemic Patients by L-Arginine. The Lancet, 338, 1546-1550. 
https://doi.org/10.1016/0140-6736(91)92372-9

[55] Tousoulis, D., Antoniades, C., Tentolouris, C., Goumas, G., Stefanadis, C. and Toutouzas, P. (2002) L-Arginine in Cardiovascular Disease: Dream or Reality? Vascular Medicine, 7, 203-211. https://doi.org/10.1191/1358863x02vm434ra

[56] Vockley, J.G., Jenkinson, C.P., Shukla, H., Kern, R.M., Grody, W.W. and Cederbaum, S.D. (1996) Cloning and Characterization of the Human Type II Arginase Gene. Genomics, 38, 118-123. https://doi.org/10.1006/geno.1996.0606

[57] Reczkowski, R.S. and Ash, D.E. (1994) Rat Liver Arginase: Kinetic Mechanism, Alternate Substrates, and Inhibitors. Archives of Biochemistry and Biophysics, 312, 31-37.

[58] Dzik, J.M. (2014) Evolutionary Roots of Arginase Expression and Regulation. Frontiers in Immunology, 5, 544. https://doi.org/10.3389/fimmu.2014.00544

[59] Caldwell, R.B., Toque, H.A., Narayanan, S.P. and Caldwell, R.W. (2015) Arginase: An Old Enzyme with New Tricks. Trends in Pharmacological Sciences, 36, 395-405. https://doi.org/10.1016/j.tips.2015.03.006

[60] Lange, P.S., Langley, B., Lu, P. and Ratan, R.R. (2004) Novel Roles for Arginase in Cell Survival, Regeneration, and Translation in the Central Nervous System. The Journal of Nutrition, 134, 2812S-2817S.

[61] Stewart, J. and Caron, H. (1977) Arginases of Mouse Brain and Liver. Journal of Neurochemistry, 29, 657-663. https://doi.org/10.1111/j.1471-4159.1977.tb07783.x

[62] Peters, D., Berger, J., Langnaese, K., Derst, C., Madai, V.I., Krauss, M., Fischer, K.D., Veh, R.W. and Laube, G. (2013) Arginase and Arginine Decarboxylase-Where Do the Putative Gate Keepers of Polyamine Synthesis Reside in Rat Brain? PLoS ONE, 8, e66735. https://doi.org/10.1371/journal.pone.0066735

[63] Polis, B., Kolluru, D.S., Elliott, E., Gil-Henn, H. and Samson, A.O. (2018) L-Norvaline Reverses Cognitive Decline and Synaptic Loss in a Murine Model of Alzheimer's Disease.

[64] Morris, S.M., Bhamidipati, D. and Kepka-Lenhart, D. (1997) Human Type II Arginase: Sequence Analysis and Tissue-Specific Expression. Gene, 193, 157-161. https://doi.org/10.1016/S0378-1119(97)00099-1

[65] Jones, M.E., Anderson, A.D., Anderson, C. and Hodes, S. (1961) Citrulline Synthesis in Rat Tissues. Archives of Biochemistry and Biophysics, 95, 499-507. https://doi.org/10.1016/0003-9861(61)90182-5

[66] Herzfeld, A. and Raper, S.M. (1976) The Heterogeneity of Arginases in Rat Tissues. Biochemical Journal, 153, 469-478. https://doi.org/10.1042/bj1530469

[67] Sidney, M. and Morris, J. (1992) Regulation of Enzymes of the Urea Cycle and Arginine Metabolism. Annual Review of Nutrition, 12, 81-101. https://doi.org/10.1146/annurev.nu.12.070192.000501

[68] Ryoo, S., Bhunia, A., Chang, F., Shoukas, A., Berkowitz, D.E. and Romer, L.H. (2011) OxLDL-Dependent Activation of Arginase II Is Dependent on the LOX-1 Receptor and Downstream RhoA Signaling. Atherosclerosis, 214, 279-287. https://doi.org/10.1016/j.atherosclerosis.2010.10.044

[69] Pandey, D., Bhunia, A., Oh, Y.J., Chang, F., Bergman, Y., Kim, J.H., Serbo, J., Boronina, T.N., Cole, R.N., Van Eyk, J., Remaley, A.T., Berkowitz, D.E. and Romer, L.H. (2014) OxLDL Triggers Retrograde Translocation of Arginase2 in Aortic Endothelial Cells via ROCK and Mitochondrial Processing Peptidase. Circulation Research, 115, 450-459. https://doi.org/10.1161/CIRCRESAHA.115.304262

[70] Terheggen, H.G. and Tomaszewski, L. (1985) Human Salivary Arginase and Its De- 
ficiency in Argininaemia1. Clinical Chemistry and Laboratory Medicine, 23, 337-342.

[71] Esch, F., Lin, K.I., Hills, A., Zaman, K., Baraban, J.M., Chatterjee, S., Rubin, L., Ash, D.E. and Ratan, R.R. (1998) Purification of a Multipotent Antideath Activity from Bovine Liver and Its Identification as Arginase: Nitric Oxide-Independent Inhibition of Neuronal Apoptosis. Journal of Neuroscience, 18, 4083-4095.

http://www.ncbi.nlm.nih.gov/pubmed/9592089 https://doi.org/10.1523/JNEUROSCI.18-11-04083.1998

[72] Deng, K., He, H., Qiu, J., Lorber, B., Bryson, J.B. and Filbin, M.T. (2009) Increased Synthesis of Spermidine as a Result of Upregulation of Arginase I Promotes Axonal Regeneration in Culture and in Vivo. Journal of Neuroscience, 29, 9545-9552. https://doi.org/10.1523/JNEUROSCI.1175-09.2009

[73] Pernow, J. and Jung, C. (2013) Arginase as a Potential Target in the Treatment of Cardiovascular Disease: Reversal of Arginine Steal? Cardiovascular Research, 98, 334-343. https://doi.org/10.1093/cvr/cvt036

[74] Gueli, M.C. and Taibi, G. (2013) Alzheimer's Disease: Amino Acid Levels and Brain Metabolic Status. Neurological Sciences, 34, 1575-1579. https://doi.org/10.1007/s10072-013-1289-9

[75] Xu, J., Begley, P., Church, S.J., Patassini, S., Hollywood, K.A., Jüllig, M., Curtis, M.A., Waldvogel, H.J., Faull, R.L.M., Unwin, R.D. and Cooper, G.J.S. (2016) Graded Perturbations of Metabolism in Multiple Regions of Human Brain in Alzheimer's Disease: Snapshot of a Pervasive Metabolic Disorder. Biochimica et Biophysica Acta (BBA)_Molecular Basis of Disease, 1862, 1084-1092. https://doi.org/10.1016/j.bbadis.2016.03.001

[76] Patassini, S., Begley, P., Reid, S.J., Xu, J., Church, S.J., Curtis, M., Dragunow, M., Waldvogel, H.J., Unwin, R.D., Snell, R.G., Faull, R.L.M. and Cooper, G.J.S. (2015) Identification of Elevated Urea as a Severe, Ubiquitous Metabolic Defect in the Brain of Patients with Huntington's Disease. Biochemical and Biophysical Research Communications, 468, 161-166. https://doi.org/10.1016/j.bbrc.2015.10.140

[77] Handley, R.R., Reid, S.J., Brauning, R., Maclean, P., Mears, E.R., Fourie, I., Patassini, S., Cooper, G.J.S., Rudiger, S.R., McLaughlan, C.J., Verma, P.J., Gusella, J.F., MacDonald, M.E., Waldvogel, H.J., Bawden, C.S., Faull, R.L.M. and Snell, R.G. (2017) Brain Urea Increase Is an Early Huntington's Disease Pathogenic Event Observed in a Prodromal Transgenic Sheep Model and HD Cases. Proceedings of the National Academy of Sciences, 114, E11293-E11302.

https://doi.org/10.1073/pnas.1711243115

[78] Hansmannel, F., Sillaire, A., Kamboh, M.I., Lendon, C., Pasquier, F., Hannequin, D., Laumet, G., Mounier, A., Ayral, A.M., Dekosky, S.T., Hauw, J.J., Berr, C., Mann, D., Amouyel, P., Campion, D. and Lambert, J.C. (2010) Is the Urea Cycle Involved in Alzheimer's Disease? Journal of Alzheimer's Disease, 21, 1013-1021. https://doi.org/10.3233/JAD-2010-100630

[79] Narayanan, S.P., Xu, Z., Putluri, N., Sreekumar, A., Lemtalsi, T., Caldwell, R.W. and Caldwell, R.B. (2014) Arginase 2 Deficiency Reduces Hyperoxia-Mediated Retinal Neurodegeneration through the Regulation of Polyamine Metabolism. Cell Death \& Disease, 5, e1075. https://doi.org/10.1038/cddis.2014.23

[80] Pernet, V., Bourgeois, P. and Di Polo, A. (2007) A Role for Polyamines in Retinal Ganglion Cell Excitotoxic Death. Journal of Neurochemistry, 103, 1481-1490. https://doi.org/10.1111/j.1471-4159.2007.04843.x

[81] Yepuri, G., Velagapudi, S., Xiong, Y., Rajapakse, A.G., Montani, J.P., Ming, X.F. and 
Yang, Z. (2012) Positive Crosstalk between Arginase-II and S6K1 in Vascular Endothelial Inflammation and Aging. Aging Cell, 11, 1005-1016. https://doi.org/10.1111/acel.12001

[82] Ming, X.-F. and Yang, Z. (2013) Functions and Mechanisms of Arginase in Age-Associated Cardiovascular Diseases. Current Translational Geriatrics and Gerontology Reports, 2, 268-274. https://doi.org/10.1007/s13670-013-0060-7

[83] Xiong, Y., Yepuri, G., Montani, J.P., Ming, X.F. and Yang, Z. (2017) Arginase-II Deficiency Extends Lifespan in Mice. Frontiers in Physiology, 8, 682. https://doi.org/10.3389/fphys.2017.00682

[84] Shosha, E., Xu, Z., Yokota, H., Saul, A., Rojas, M., Caldwell, R.W., Caldwell, R.B. and Narayanan, S.P. (2016) Arginase 2 Promotes Neurovascular Degeneration during Ischemia/Reperfusion Injury. Cell Death \& Disease, 7, e2483. https://doi.org/10.1038/cddis.2016.295

[85] Bensemain, F., Hot, D., Ferreira, S., Dumont, J., Bombois, S., Maurage, C., Huot, L., Hermant, X., Levillain, E., Hubans, C., Hansmannel, F., Chapuis, J., Hauw, J.-J., Schraen, S., Lemoine, Y., Buée, L., Berr, C., Mann, D., Pasquier, F., Amouyel, P. and Lambert, J.-C. (2009) Evidence for Induction of the Ornithine Transcarbamylase Expression in Alzheimer's Disease. Molecular Psychiatry, 14, 106-116. https://doi.org/10.1038/sj.mp.4002089

[86] Inoue, K., Tsutsui, H., Akatsu, H., Hashizume, Y., Matsukawa, N., Yamamoto, T. and Toyo'Oka, T. (2013) Metabolic Profiling of Alzheimer's Disease Brains. Scientific Reports, 3, Article No. 2364. https://doi.org/10.1038/srep02364

[87] Morrison, L.D. and Kish, S.J. (1995) Brain Polyamine Levels Are Altered in Alzheimer's Disease. Neuroscience Letters, 197, 5-8. https://doi.org/10.1016/0304-3940(95)11881-V

[88] Lichter-Konecki, U. (2016) Defects of the Urea Cycle. Translational Science of Rare Diseases, 1, 23-43. https://doi.org/10.3233/TRD-160002

[89] Ivanenkov, Y.A. and Chufarova, N.V. (2014) Small-Molecule Arginase Inhibitors. Pharmaceutical Patent Analyst, 3, 65-85. https://doi.org/10.4155/ppa.13.75

[90] Shearer, J.D., Richards, J.R., Mills, C.D. and Caldwell, M.D. (1997) Differential Regulation of Macrophage Arginine Metabolism: A Proposed Role in Wound Healing. American Journal of Physiology, 272, E181-E190.

[91] El-Bassossy, H.M., El-Fawal, R., Fahmy, A. and Watson, M.L. (2013) Arginase Inhibition Alleviates Hypertension in the Metabolic Syndrome. British Journal of Pharmacology, 169, 693-703. https://doi.org/10.1111/bph.12144

[92] Hunter, A. and Downs, E. (1945) The Inhibition of Arginase by Amino Acids. The Journal of Biological Chemistry, 157, 427-446.

[93] Huynh, N., Harris, E., Chin-Dusting, J. and Andrews, K. (2009) The Vascular Effects of Different Arginase Inhibitors in Rat Isolated Aorta and Mesenteric Arteries. British Journal of Pharmacology, 156, 84-93. https://doi.org/10.1111/j.1476-5381.2008.00036.x

[94] El-Bassossy, H.M., El-Fawal, R. and Fahmy, A. (2012) Arginase Inhibition Alleviates Hypertension Associated with Diabetes: Effect on Endothelial Dependent Relaxation and NO Production. Vascular Pharmacology, 57, 194-200. https://doi.org/10.1016/j.vph.2012.01.001

[95] De, A., Singh, M.F., Singh, V., Ram, V. and Bisht, S. (2016) Treatment Effect of 1-Norvaline on the Sexual Performance of Male Rats with Streptozotocin Induced Diabetes. European Journal of Pharmacology, 771, 247-254. 
https://doi.org/10.1016/j.ejphar.2015.12.008

[96] Alber, J., McGarry, K., Noto, R.B. and Snyder, P.J. (2018) Use of Eflornithine (DFMO) in the Treatment of Early Alzheimer's Disease: A Compassionate Use, Single-Case Study. Frontiers in Aging Neuroscience, 10, 60. https://doi.org/10.3389/fnagi.2018.00060

[97] Metcalf, B.W., Bey, P., Danzin, C., Jung, M.J., Casara, P. and Vevert, J.P. (1978) Catalytic Irreversible Inhibition of Mammalian Ornithine Decarboxylase (E. C. 4.1.1.17) by Substrate and Product Analogues. Journal of the American Chemical Society, 100, 2551-2553. https://doi.org/10.1021/ja00476a050

[98] Selamnia, M., Mayeur, C., Robert, V. and Blachier, F. (1998) Alpha Difluoromethylornithine (DFMO) as a Potent Arginase Activity Inhibitor in Human Colon Carcinoma Cells. Biochemical Pharmacology, 55, 1241-1245.

https://doi.org/10.1016/S0006-2952(97)00572-8

[99] Oddo, S., Caccamo, A., Shepherd, J.D., Murphy, M.P., Golde, T.E., Kayed, R., Metherate, R., Mattson, M.P., Akbari, Y. and LaFerla, F.M. (2003) Triple-Transgenic Model of Alzheimer's Disease with Plaques and Tangles: Intracellular A $\beta$ and Synaptic Dysfunction. Neuron, 39, 409-421. https://doi.org/10.1016/S0896-6273(03)00434-3

[100] Chang, C.I., Liao, J.C. and Kuo, L. (1998) Arginase Modulates Nitric Oxide Production in Activated Macrophages. American Journal of Physiology, 274, H342-H348.

[101] El-Bassossy, H.M., El-Fawal, R., Fahmy, A. and Watson, M.L. (2013) Arginase Inhibition Alleviates Hypertension in the Metabolic Syndrome. British Journal of Pharmacology, 169, 693-703. https://doi.org/10.1111/bph.12144

[102] Ming, X.F., Rajapakse, A.G., Carvas, J.M., Ruffieux, J. and Yang, Z. (2009) Inhibition of S6K1 Accounts Partially for the Anti-Inflammatory Effects of the Arginase Inhibitor L-Norvaline. BMC Cardiovascular Disorders, 9, 12. https://doi.org/10.1186/1471-2261-9-12

[103] Wang, C., Yu, J.-T., Miao, D., Wu, Z.-C., Tan, M.-S. and Tan, L. (2014) Targeting the mTOR Signaling Network for Alzheimer's Disease Therapy. Molecular Neurobiology, 49, 120-135. https://doi.org/10.1007/s12035-013-8505-8

[104] Tramutola, A., Lanzillotta, C. and Di Domenico, F. (2017) Targeting mTOR to Reduce Alzheimer-Related Cognitive Decline: From Current Hits to Future Therapies. Expert Review of Neurotherapeutics, 17, 33-45. https://doi.org/10.1080/14737175.2017.1244482

[105] Davoodi, J., Drown, P.M., Bledsoe, R.K., Wallin, R., Reinhart, G.D. and Hutson, S.M. (1998) Overexpression and Characterization of the Human Mitochondrial and Cytosolic Branched-Chain Aminotransferases. The Journal of Biological Chemistry, 273, 4982-4989. https://doi.org/10.1074/jbc.273.9.4982

[106] Chen, J. and Herrup, K. (2012) Glutamine Acts as a Neuroprotectant against DNA Damage, Beta-Amyloid and $\mathrm{H}_{2} \mathrm{O}_{2}$-Induced Stress. PLoS ONE, 7, e33177. https://doi.org/10.1371/journal.pone.0033177

[107] Griffin, J.W.D. and Bradshaw, P.C. (2017) Amino Acid Catabolism in Alzheimer's Disease Brain: Friend or Foe? Oxidative Medicine and Cellular Longevity, 2017, Article ID: 5472792.

[108] Sweatt, A.J., Garcia-Espinosa, M.A., Wallin, R. and Hutson, S.M. (2004) Branched-Chain Amino Acids and Neurotransmitter Metabolism: Expression of Cytosolic Branched-Chain Aminotransferase (BCATC) in the Cerebellum and Hippocampus. Journal of Comparative Neurology, 477, 360-370.

https://doi.org/10.1002/cne.20200 
[109] Li, H., Ye, D., Xie, W., Hua, F., Yang, Y., Wu, J., Gu, A. and Ren, Y. (2018) Defect of Branched-Chain Amino Acid Metabolism Promotes the Development of Alzheimer's Disease by Targeting the mTOR Signaling. Bioscience Reports, 38, BSR20180127. https://doi.org/10.1042/BSR20180127

[110] Peluffo, H., Acarin, L., Arís, A., González, P., Villaverde, A., Castellano, B. and González, B. (2006) Neuroprotection from NMDA Excitotoxic Lesion by $\mathrm{Cu} / \mathrm{Zn}$ Superoxide Dismutase Gene Delivery to the Postnatal Rat Brain by a Modular Protein Vector. BMC Neuroscience, 7, 1-11. https://doi.org/10.1186/1471-2202-7-35

[111] Yu, X., Rajala, R.V.S., McGinnis, J.F., Li, F., Anderson, R.E., Yan, X., Li, S., Elias, R.V., Knapp, R.R., Zhou, X. and Cao, W. (2004) Involvement of Insulin/Phosphoinositide 3-Kinase/Akt Signal Pathway in 17 $\beta$-Estradiol-Mediated Neuroprotection. The Journal of Biological Chemistry, 279, 13086-13094. https://doi.org/10.1074/jbc.M313283200

[112] Gao, H., Tao, Y., He, Q., Song, F. and Saffen, D. (2015) Functional Enrichment Analysis of Three Alzheimer's Disease Genome-Wide Association Studies Identities DAB1 as a Novel Candidate Liability/Protective Gene. Biochemical and Biophysical Research Communications, 463, 490-495. https://doi.org/10.1016/j.bbrc.2015.05.044

[113] Li, Y., Park, J.S., Deng, J.H. and Bai, Y. (2006) Cytochrome c Oxidase Subunit IV Is Essential for Assembly and Respiratory Function of the Enzyme Complex. Journal of Bioenergetics and Biomembranes, 38, 283-291.

https://doi.org/10.1007/s10863-006-9052-Z 